\title{
Recherches sur l'immunisation des porcelets contre la maladie de Teschen
}

\author{
por H. SERRES
}

Le Laboratoire central de l'Elevage, à Tananarive, prépare depuis 1954 un vaccin contre la maladie de Teschen.

La technique de préparation de ce vaccin a évolué depuis sa création, la transformation la plus importante étant l'introduction des cultures de tissus par Bourdin et coll. [[1] et [2]). Toutefois, un principe est resté, c'est celui de l'utilisation d'un virus vivant et pleinement virulent. Cette technique peut être appliquée car l'inoculation sous-cutanéé de virus de Teschen, quelle que soit la virulence de la souche, n'a jamais permis de reproduire expérimentalement la maladie. Bien que des expériences précédentes nous aient montré la possibilité d'immuniser d'excellente façon avec du virus inactivé, nous utilisons toujours, pour le moment, le virus vivant dont une longue pratique nous a prouvé l'efficacité.

Afin de progresser encore, nous avons entrepris l'étude de quelques facteurs susceptibles de conditionner l'immunisation. C'est ce que nous allons exposer ci-après.

\section{I. - TITRE EN VIRUS DU VACCIN}

Nous envisagerons d'abord l'importante ques. tion de la teneur du vaccin en unités virulentes.

Cette étude a été pratiquée à l'aide de virus récolté après la lyse d'une culture de ceilules épithéliales de rein de porcelet (la souche étant au $34^{\text {e }}$ passage sur cellules). Le titrage a été pratiqué sur culture de cellules en tubes roulants selon la technique décrite par Bourdin et coll. (1). Il a donné 10-- DL 50 par millilitre. Puis le liquide de récolte a été dilué pour obtenir les concentrations suivantes :

$$
10^{-6}, 10^{-4}, 10^{-2} \mathrm{DL} 50 \text { par ml. }
$$

Avec chaque dilution, un lot de vaccin a été préparé, par addition d'un volume égal de gel d'alumine à 2 p. 100.

Cinq porcelets Large-White de deux mois. pesant $10 \mathrm{~kg}$ environ, ont été inoculés avec chaque série lon a pratiqué deux injections souscutanées de $5 \mathrm{ml}$ à 15 jours d'intervalle par animal). Vingt jours après la deuxième vaccination. les animaux ont été éprouvés :par inoculation intra-cérébrale de 0,25 $\mathrm{ml}$ de souche entretenue sur cerveau, diluée à $10^{-3}$, ce qui représente $1.000 \mathrm{DL} 50$ pour le porcelet. Cinq porcelets témoins ont été inoculés de la même manière. Les animaux ont été observés pendant 30 jours; pour ceux qui ont succombé l'examen histopathologique des moelles lombaires et des bulbes fut pratiqué (les lésions de poliomyélite aiguë sont caractéristiques de la maladie de Teschen à Madagascar).

Le tableau $A$ indique les faits expérimentaux. Ces résultats montrent que :

- A $10^{-2} \mathrm{DL} 50 / \mathrm{ml}$ on n'obtient aucune immunité, puisque le nombre d'animaux frappés par la maladie est égal à celui noté pour les animaux témoins (4 sur 5).

- A $10^{-4} \mathrm{DL} 50 / \mathrm{ml}$ une immunité certaine s'établit, mais d'une manière irrégulière, puisque deux animaux sur cinq succombent à l'épreuve.

- A $10^{-6} \mathrm{DL} 50 / \mathrm{ml}$ le résultat est plus satisfaisant, mais encore partiel : un animal sur cinq succombe. 
TABLEAU A

\begin{tabular}{|c|c|c|c|c|}
\hline Lot & $\begin{array}{c}\text { Porcelet } \\
\mathbb{N}^{\circ}\end{array}$ & Résultats de liépreuve & Symptômes & $\begin{array}{l}\text { Histo- } \\
\text { pathologie }\end{array}$ \\
\hline $\begin{array}{l}\text { No } 1 \\
\text { Virus d } \\
10^{-8} \text { DL } 50 / \mathrm{ml}\end{array}$ & $\begin{array}{l}1510 \\
1497 \\
1521 \\
1506 \\
1513\end{array}$ & $\begin{array}{l}\text { Résistant après } 30 \text { jours } \\
\text { Résistant après } 30 \text { jours } \\
\text { Résistant après } 30 \text { jours } \\
\text { Résistant après } 30 \text { jours } \\
\text { Résiatant après } 30 \text { jours }\end{array}$ & $\begin{array}{l}- \\
- \\
- \\
-\end{array}$ & $\begin{array}{l}- \\
- \\
- \\
-\end{array}$ \\
\hline $\begin{array}{c}N^{\circ} 2 \\
\text { Virus a } \\
10^{-6} \text { DL } 50 / \mathrm{ml}\end{array}$ & $\begin{array}{r}1295 \\
920 \\
1294 \\
911 \\
1017\end{array}$ & $\begin{array}{l}\text { Résistant après } 30 \text { jours } \\
\text { Résistant après } 30 \text { jours } \\
\text { Mort } 10 \text { jours après épreuve } \\
\text { Résistant après } 30 \text { jours } \\
\text { Résistant après } 30 \text { jours }\end{array}$ & $\begin{array}{c}\text { - } \\
\text { Fara?ysie totale } \\
\text { - }\end{array}$ & $\begin{array}{l}- \\
+ \\
+ \\
-\end{array}$ \\
\hline $\begin{array}{c}\text { No } 3 \\
\text { Virus a } \\
10^{-4} \text { DL } 50 / \mathrm{mI}\end{array}$ & $\begin{array}{l}1286 \\
1291 \\
1011 \\
1018 \\
1012\end{array}$ & $\begin{array}{l}\text { Mort } 11 \text { jours après épreuve } \\
\text { Mort 10 jours après épreuve } \\
\text { Résistant après } 30 \text { jours } \\
\text { Résigtant après } 30 \text { jouzs } \\
\text { Résistant après } 30 \text { jours }\end{array}$ & $\begin{array}{l}\text { Paralysie totale } \\
\text { Paralysie totale } \\
\text { - } \\
- \\
-\end{array}$ & $\begin{array}{l}+ \\
\dot{+} \\
- \\
- \\
-\end{array}$ \\
\hline $\begin{array}{c}\text { No } 4 \\
\text { Virus a } \\
10^{-2} \text { DL } 50 / \mathrm{ml}\end{array}$ & $\begin{array}{l}1300 \\
1287 \\
1299 \\
1019 \\
1289\end{array}$ & $\begin{array}{l}\text { Mort } 8 \text { joura après ćprowe } \\
\text { Mort } 9 \text { jours après épreure } \\
\text { Mort } 8 \text { jours après épreuve } \\
\text { Résistant après } 30 \text { jours } \\
\text { Mort } 8 \text { jours après épreurs }\end{array}$ & $\begin{array}{l}\text { Paralyoie totale } \\
\text { Paraiysie totale } \\
\text { Faralysie totale } \\
\text { - } \\
\text { Paralysie tctaie }\end{array}$ & $\begin{array}{l}+ \\
+ \\
+ \\
- \\
+\end{array}$ \\
\hline $\begin{array}{l}\text { Iొ } 5 \\
\text { Témoins } \\
\text { d'épreuvs }\end{array}$ & $\begin{array}{r}908 \\
1013 \\
1288 \\
1298 \\
1296\end{array}$ & $\begin{array}{l}\text { Résistant après } 30 \text { jours } \\
\text { Perelysie après } 12 \text { jours } \\
\text { Mort } 10 \text { jours après ćpreuve } \\
\text { liort } 9 \text { jours après éprouve } \\
\text { liort } 10 \text { jours après épreuve }\end{array}$ & $\begin{array}{l}\text { Paralisie pozistanto. } \\
\text { liest pas mort. } \\
\text { Paraiysie towale } \\
\text { Faralyaie totala } \\
\text { Paralysie totale }\end{array}$ & $\begin{array}{l}- \\
- \\
+ \\
+ \\
+\end{array}$ \\
\hline
\end{tabular}

- A $10^{-s} \mathrm{DL} 50 / \mathrm{ml}$ l'immunisation est excellente, tous les animaux résistant à l'épreuve.

Nous concluons qu'on devrait obtenir régulièrement $10^{-s} \mathrm{DL} 50 / \mathrm{ml}$ pour avoir un vaccin de grand pouvoir immunogène. Toutefois, si nous considérons la sévérité de l'épreuve effectuée dans l'expérience (1.000 DL 50 pour le porcelet), nous pouvons affirmer que les récoltes donnant $10^{-6}$ DL 50 sont douées d'un pouvoir vaccinant très important. Elles peuvent être utilisées pour la préparation de vaccins dont on peut attendre une efficacité certaine.

\section{II. - UTILITE DU GEL D'ALUMINE DANS LA REVACCINATION}

L'utilisation du gel d'alumine comme adjuvant est largement répanduc en immunóogic vétérinaire.

L'expórimentation nous a montré son intérêt primordial dans la vaccination contre la maladie de Teschen (3). Les modalités dé l'activité de ce gel d'alumine n'ont cependant pas été précisées. La lecture des importants travaux de d'Antona et Piazzi sur l'immunisation antidiphtsrique du cobaye (4) inspirent un complément d'expérimentation. Reprenons leurs conclusions : "Lors de la stimulation primaire, les antigènes adsorbés ou émulsionnés dans l'huile ont un cffet incomparablement supérieur à celui obtenu avec les mêmes antigènes fluides (naturels ou purifiés), leur action se traduisant par une production plus intensive ef pus rapide d'anticorps, et par une réactivité acquise (immunité potentielle) conzidérablement plus développée.

"Lors de la stimulation secondaire ou de rappel on observe une inversion des phénomènes; l'immunité oblenue - si on corlsidère la quantité d'anticorps apparue dans le sang est nettement favorisée par les stimuli adminis- 
trés avec des antigènes fluides, mais non par des antigènes adsorbés ou émulsionnés dans l'huile. »

En serait-it de même pour l'immunisation antivirus de Teschen ? Un résultat nous est déjà connu : plusieurs injections de virus adsorbé donnent de meilleurs résultats que ia même quantité d'antigène utilisée sous forme fluide. Nous avons réalisé l'expérimentation décrite ciaprès pour comparer les immunités precurées par :

- deux stimuli « antigène adsorbé »,

- un stimulus « antigène adsorbé » sui $\because$ d'ur $^{\circ}$ stimulus 《 antigène fluide ».

Nous avons utilisé des porce èj Large-Wr-e ae deux mois. Une prise de sang a été faite à enaque animal avant toute chose, afin de vérifier 'absence d'anticorps neutralisants dans leur sérum.

Puis ies deux vaccinations sont effectuées à 15 jours d'intervalle, à l'aide d'une souche titrant $10^{-5}{ }_{1}^{65} \mathrm{DL} 50 / \mathrm{m}$ ! pour cellules en tubes roulants. Vingt jours après la deuxième injection une nouvelle prise de sang permettra de titrer les anticorps apparus fon détermine la dilution maximum inhibitrice de la cytolyse causée par 100 DL 50 de virus). Après cette prise de sang, iez corcelets sont éprouvés comme dans l'expérence précédente: l'observation dure 30 jours inir coleau B!.

\section{TEELEEE D}

LOT No $1\left\{\begin{array}{l}\text { lère inoculation : } 5 \mathrm{ml} \text { de vaccin adsorbé } \\ \text { 2ème inoculaticn : } 5 \mathrm{ml} \text { de racin adsorbé }\end{array}\right.$

\begin{tabular}{|c|c|c|c|c|c|}
\hline $\begin{array}{c}\text { Porcelet } \\
\mathrm{Na}^{\mathrm{a}}\end{array}$ & $\begin{array}{l}\text { Anti } \\
\text { avant }\end{array}$ & $\begin{array}{l}\text { a.pres } \\
\text { a.pres }\end{array}$ & Epreure & Sycptômes & $\begin{array}{c}\text { Lésions } \\
\text { histolc Eiques }\end{array}$ \\
\hline $\begin{array}{l}1266 \\
1250 \\
1276 \\
1253 \\
1268 \\
1269\end{array}$ & $\begin{array}{l}0 \\
0 \\
0 \\
0 \\
0 \\
0\end{array}$ & $\begin{array}{l}1 / 40 \\
1 / 20 \\
1 / 20 \\
1 / 10 \\
1 / 20 \\
1 / 80\end{array}$ & $\begin{array}{l}\text { Résistant après } 30 \text { jcurs } \\
\text { Mort } 21 \text { jours après épzeure } \\
\text { Résistant après } 30 \text { jours } \\
\text { Résistant après } 30 \text { jours } \\
\text { Résistant après } 30 \text { jours } \\
\text { Mort } 22 \text { jours afrès épreure }\end{array}$ & $\begin{array}{c}\text { Paralysie totale } \\
- \\
- \\
\text { Paralysie totale }\end{array}$ & $\begin{array}{l}- \\
\dot{z} \\
- \\
- \\
\dot{4}\end{array}$ \\
\hline \multicolumn{3}{|c|}{$\begin{array}{l}\text { Yoyense } \\
\frac{1}{31}\end{array}$} & $\begin{array}{c}\text { Morts : } 2 \sin 6 \\
\text { Sésistants : } 4 \text { sur } 6\end{array}$ & & : \\
\hline
\end{tabular}

LOT N०2 $\left\{\begin{array}{l}\text { lère inoculation : } 5 \text { ml de racoin adsorbé } \\ \text { 2ème inoculation : } 2,5 \text { ml d'antigène fluide }\end{array}\right.$

\begin{tabular}{|c|c|c|c|c|c|}
\hline $\begin{array}{l}\text { Porcelet } \\
\qquad \mathrm{N}^{\circ}\end{array}$ & $\begin{array}{l}\text { Anti } \\
\text { avant }\end{array}$ & $\begin{array}{l}\text { corps } \\
\text { après }\end{array}$ & Epreuve & Syzpticn 38 & $\begin{array}{l}\text { Lésions } \\
\text { histologiques }\end{array}$ \\
\hline $\begin{array}{l}1258 \\
1270 \\
1260 \\
1274 \\
1255 \\
1254 \\
1249 \\
1273\end{array}$ & $\begin{array}{l}0 \\
0 \\
0 \\
0 \\
0 \\
0 \\
0 \\
0\end{array}$ & $\begin{array}{l}1 / 20 \\
1 / 40 \\
1 / 40 \\
1 / 40 \\
1 / 40 \\
1 / 40 \\
1 / 10 \\
1 / 20\end{array}$ & $\begin{array}{l}\text { Résistant après } 30 \text { jours } \\
\text { Résistant après } 30 \text { jours } \\
\text { Mort } 10 \text { jours apres epreurve } \\
\text { Résistant apres } 30 \text { jours } \\
\text { Mort } 11 \text { jours après épreure } \\
\text { Résistant après } 30 \text { jours } \\
\text { Kort } 10 \text { jours après épreure } \\
\text { Kisistant eprès } 30 \text { jours }\end{array}$ & $\begin{array}{l}\text { - } \\
\text { Farelysie totale } \\
\text { E- totale } \\
\text { Falyie totale } \\
\text { Paralys: totale } \\
\text { - }\end{array}$ & $\begin{array}{l}\dot{-} \\
\dot{+} \\
\overline{+} \\
\dot{+} \\
\dot{+} \\
-\end{array}$ \\
\hline \multicolumn{6}{|c|}{ Résistants : 5 sur 8} \\
\hline
\end{tabular}


TABLFAU $c$

\begin{tabular}{|c|c|c|c|c|c|c|c|c|}
\hline \multicolumn{3}{|c|}{ Intervalle 12 jours } & \multicolumn{3}{|c|}{ Intervalle 20 jours } & \multicolumn{3}{|c|}{ Intervalle 30 jours } \\
\hline \multirow{2}{*}{$\begin{array}{c}\text { Porcelet } \\
\qquad N^{0}\end{array}$} & \multicolumn{2}{|c|}{ Anticorps } & \multirow{2}{*}{$\begin{array}{c}\text { Porcelet } \\
\mathrm{N}^{\circ}\end{array}$} & \multicolumn{2}{|c|}{ Anticorps } & \multirow{2}{*}{$\begin{array}{c}\text { Porcelet } \\
\mathrm{N}^{\circ}\end{array}$} & \multicolumn{2}{|c|}{ Anticorps } \\
\hline & avant & après & & avant & après & & avant & après \\
\hline 906 & 0 & $1 / 40$ & 1031 & 0 & $1 / 160$ & 1041 & 0 & $1 / 20$ \\
\hline 918 & 0 & $1 / 20$ & 1032 & 0 & $1 / 160$ & 1020 & 0 & $1 / 160$ \\
\hline 907 & 0 & $1 / 80$ & 1029 & 0 & $1 / 20$ & 1043 & 0 & $1 / 80$ \\
\hline 917 & 0 & $1 / 80$ & 1030 & 0 & $1 / 40$ & 1040 & 0 & $1 / 160$ \\
\hline 924 & 0 & $1 / 20$ & 1026 & 0 & $1 / 40$ & 1025 & 0 & $1 / 160$ \\
\hline 905 & 0 & $1 / 40$ & 1035 & 0 & $1 / 40$ & 1022 & 0 & $1 / 40$ \\
\hline 914 & 0 & $1 / 60^{\prime}$ & 1023 & 0 & $1 / 160$ & 1027 & 0 & $1 / 10$ \\
\hline 912 & 0 & $1 / 80$ & 1049 & 0 & $1 / 20$ & 1033 & 0 & $1 / 40$ \\
\hline \multirow[t]{2}{*}{916} & 0 & $1 / 80$ & 1024 & 0 & $1 / 160$ & 1039 & 0 & $1 / 10$ \\
\hline & & & 1042 & 0 & $1 / 40$ & & & \\
\hline \multicolumn{3}{|c|}{ Titre neutralisant } & \multicolumn{3}{|c|}{ Titre noutralisant } & \multicolumn{3}{|c|}{ Titre neutraliaant } \\
\hline \multicolumn{3}{|c|}{ moyen $1 / 43$} & \multicolumn{3}{|c|}{ moyen $1 / 45$} & \multicolumn{3}{|c|}{ moyen $1 / 26$} \\
\hline
\end{tabular}

Les résultats expérimentaux ci-dessus permettent de voir qu'il n'y a pas de différence sensible dans l'immunité obtenue, suivant qu'on utilise ou non le gel d'alumine dans la deuxième injection. On est en droit de conclure, en accord avec d'Antonna et Piazzi, que l'adsorption de l'antigène prend son intérêt au moment du stimulus primaire.

En contrepartie, l'expérience ne fait pas ressortir de plus mauvais résultats avec le gel d'alumine dans la deuxième injection qu'en son absence labstraction faite de «l'immunité potentielle », pour laquelle des essais complémentaires seraient nécessaires).

II serait bien incommode d'avoir deux vaccins différents, l'un adsorbé, l'autre non, à utiliser dans les campagnes de vaccination; nous sommes donc conduits à conserver le gel d'alumine pour des raisons de conditionnement et d'utilisation.

\section{III. - INTERVALLE ENTRE LES DEUX STIMULATIONS ANTIGENIQUES}

La pratique courante de la vaccination antiTeschen comporte deux injections. Il est certain que l'intervalle de temps qui les sépare n'est pas indifférent pour l'obtention d'un bon résultat immunologique. L'utilisation de notre virus vaccin virulent, permet de supposer qu'après l'inoculation se développe une maladie inapparente. II faudrait peut-être lui laisser le temps d'évoluer suffisamment, avant d'entreprendre la deuxième injection. Ce temps n'étant pas connu. nous avons essayé de le préciser en déterminant les anticorps apparus après des vaccinations dont les intervalles ont été variés $(12,20,30$ jours).

Vaccinations et titrages ont été effectués selon les techniques mentionnées plus haut. Les prises de sang furent pratiquées avant la première vaccination et 20 jours après la deuxième (voir tableau C).

Les résultats obtenus avec un intervalle de 30 jours sont nettement les moins bons. Avec 20 jours les résultats sont les meilleurs, mais de peu par rapport à 12 jours. Nous conseillerons donc d'espacer les vaccinations par un délai de 15 à 20 jours, en évitant de dépasser trois semaines.

Laboratoire central de l'Elevage, Tananarive. 


\section{BIBLIOGRAPHIE}

I. BOURDIN, ATANASIU, LEPINE, JACOTOT, VALLEE. - Ann. Inst. Pasteur, 1957, 93. 581.

2. BOURDIN, BUCK, JACOTOT. - Rev. Elev. Méd. vét. Pays trop., 1958, 11 (1), 17-22.
3. SERRES, BOURDIN. - Ann. Inst. Pasteur (sous presse).

4. ANTONA (d'), PIAZZI. - Rev. Immunol., 1956, 20, 317.

\section{SUMMARY}

\section{Immunisation of piglets against Teschen disease.}

The-author studied the factors influencing immunisation of piglets against Teschen Disease : He used a vaccine made with a Teschen virus grown on piglet kidney epithelial ceil tissue culture (two $5 \mathrm{ml}$. subcutaneous inoculations at 15 days interval). He noted:

1) The titre of the Teschen culture virus must be $10^{-5} \mathrm{LD} 50 / \mathrm{ml}$ to obtain a good immunity.

2) Aluminium gel does not improve the immunity when it is used with the second injection; but does not reduce it.

3) The recommended interval between the injections of vaccine is 15 to 20 days.

\section{RESUMEN}

\section{Investigaciones sobre la immunización de los cerdos jóvenes contra la enfermedad de Teschen.}

El autor estudia los factores susceptibles de establecer la inmunización de los cerdos jóvenes contra la enfermedad de Teschen, utiliza una vacuna preparada a partir de un virus de Teschen cultivado en células épiteliales de riñón de cerdo joven $(2$ inyecciones sub-cutaneas de $5 \mathrm{ml}$ con 15 dias de intervalo).

El autor saca las siguientes conclusiones:

$1^{\circ}$ El virus de Teschen cultivado debe titular $10^{-*}$ DL 50 por $\mathrm{ml}$ para que la inmunidad obtenida sea excelente.

$2^{\circ}$ En gel de hidroxido de aluminio no lleva consigo una inmunidad superior cuando es utilizado en la segunda vacunación, pero su presencia no es desfavorable.

$3^{\circ}$ El intervalo que se recomienda entre las dos inyecciones de vacuna es de 15 a 20 dias. 